\title{
The Demonstration of Linguistic, Cognitive and Socio-cultural Dimensions of Academic Literacy in Nursing Students' Written Texts
}

\author{
Asih Nurakhir ${ }^{1^{*}}$, Issy Yuliasri ${ }^{2}$, Dwi Anggani Linggar Bharati ${ }^{3}$ \\ ${ }^{1}$ Universitas Diponegoro, Semarang, Indonesia \\ ${ }^{2,3}$ English Department, Universitas Negeri Semarang, Semarang, Indonesia \\ E-mail: a.nurakhir@fk.undip.ac.id
}

\begin{abstract}
This study aimed to evaluate the demonstration of linguistic, cognitive, and sociocultural dimensions of academic literacy in the written texts produced by the students of the nursing program. A descriptive qualitative research design was used to meet the purpose of the study. Data were collected from the students' written texts, which served as the students' responses to an English quiz. Fifteen out of fifty-two students' written texts were randomly selected for the analysis. A modified scale table from the existing literature was used as a guideline during the analysis. This scale describes an assessment of the three dimensions of literacy: linguistic, cognitive, and socio-cultural. The results of the analysis showed that, in general, the students had a fair level of linguistic, cognitive, and socio-cultural dimensions of literacy. They could partially use layouts, punctuations, capitalizations, verb conjugations, and agreement as well as spelling. They also seemed to be familiar with some types of texts and generic structures, as well as linguistic features. However, there was evidence that students provided a less complete response and sometimes irrelevant information as well as an inconsistent interpretation of the subject of the text. This study indicates a high need for nursing students to improve their ability in academic literacy in English. As academic literacy is not a natural phenomenon, instead a learned ability, it should be developed and fostered in the educational institutions.
\end{abstract}

Keywords: Academic Literacy, Linguistic, Cognitive, Socio-cultural

\section{Introduction}

In the traditional perspective, literacy is defined as the ability to read and write; to date, it describes the use of socially, historically, and culturally situated practices of creating and interpreting meaning through texts (Kern, 2000). According to Gao, (2017), literacy refers to the ability to read and write words in a standard language that enables the learners to communicate in the social or professional context. Literacy frames reading and writing as complementary dimensions of written communication rather than as utterly distinct linguistic and cognitive processes (Lea \& Street, 1998). The practice of literacy, which includes reading and writing within disciplines, constitutes central processes through which students learn new subjects and develop their knowledge about new areas of study. It takes account of the cultural and contextual component of writing and reading and has important implications for an understanding of student learning (Lea \& Street, 1998).

Kern, (2000) outlines three dimensions of literacy, including linguistic, cognitive, and socio-cultural dimensions. Literacy is a linguistic process as it relies not only on knowledge of vocabulary and grammar, but also on textual organization beyond the text level, knowledge of the genre, and knowledge of conventions of spoken and written language. It is a cognitive process as it involves the links between knowledge and textual forms. Literacy is also a social practice as it is developed through apprenticeship and shaped by its users to conform to social

\footnotetext{
${ }^{*}$ Corresponding author.

Received 17 June 2019; Accepted 05 June 2020; Available online 01 September 2020 (c) 2020 JPI. All Rights Reserved
} 
needs (Kern, 2000). Literacy is a way of communicating as it is installed in a social context and always represents an interaction among individuals (Barton, 2007).

According to Wells, (1987), there are four levels of literacy: performative, functional, information, and epistemic. The performative level involves decoding simple written messages and encoding ideas into writing. The functional level emphasizes the use of literacy to cope with the demands of everyday life that involves written language, such as being able to read a popular newspaper, writing job applications, and following the instructions. The information level involves the use of literacy skills in the communication and acquisition of knowledge. Meanwhile, the epistemic level involves acting upon and transforming knowledge and experience (Wells, 1987). University students are placed at the epistemic level. Within this level, students are required to have the ability to deliver and transform knowledge through the use of language, such as writing.

Marinkovich et al., (2016) argued that literacy in an academic context is focused primarily on writing as a tool for approaching, processing, communicating, and learning disciplinary knowledge. Literacy has something to do with how people use the language, and more specifically, how they use the written language (Kress, 2003). Literacy can be demonstrated in many ways, such as academic essays, which are fundamental to academic writing (Papashane \& Hlalele, 2014). Nevertheless, academic essays are not the only types of texts through which students' literacy can be demonstrated. The writing of reports on experiments in the physical sciences and life sciences, the designing of posters and advertisements for students studying marketing or English, the production of spoken texts in the form of individual oral presentations (speeches) in various fields, group dramatic performances in the dramatic arts, and debates on issues in a variety of learning areas are some other ways through which literacy may be demonstrated (Papashane \& Hlalele, 2014).

For university students, writing plays a significant role in their study. Most times, students are demanded to write specific types of texts that are pertinent to the fields they are studying. This includes adopting a style of writing appropriate to the academic field and genre the students are writing in (Piršl et al., 2011). Student writing - rather than other language or literacy activities - has been at the top of the language agenda in expanding higher education contexts since students' written texts continue to constitute the main form of assessment, and as such writing is a 'high stakes' activity in university education. If there are problems with writing, then the students are likely to fail (Lillis \& Scott, 2007). Writing is often the factor that decides whether a student is successful at university or not and has become the key to survival in many fields of study (Piršl et al., 2011). It is a significant aspect of students' achievement (Palmer et al., 2014). In college, writing is 'a way of life' in which the majority of students' activities, either in daily duties of lectures, examinations, or charging administrative requirements, require writing skills. Without adequate ability in writing, students will find it hard to follow the learning process well, or might not even be able to complete their studies (Rahayu \& Arrasyid, 2016).

Many studies have urged the importance of assessing and improving academic literacy through writing as it plays a significant role in achieving students' academic success (Chimbganda, 2011; Defazio et al., 2010; Gao, 2017; Hyland, 2007; Lea \& Street, 2006; Marinkovich et al., 2016; Mujiyanto, 2013; Papashane \& Hlalele, 2014; Rajagukguk, T. E. B. et al., 2017). Academic literacy should be fostered in an educational institution since it is indeed not a natural phenomenon; instead, it is a learned ability (Kern, 2000). Curry, (2004) emphasizes the importance of teaching academic writing in students' native language and English, as well as the materials in order to help them achieve good academic literacy.

For most students in the EFL context, being literate in the native language does not mean being literate in the target language, in this case, is English. Being academically literate is not only a matter of applying the language conventions or rules, such as grammars, punctuations, spellings, and so on but also what is being delivered or said through the language as the language functions as the media to communicate their ideas (Rajagukguk, $T$. E. B. et al., 2017). Assessing students' literacy is then necessary to help students develop their literacy. This study aimed to evaluate how nursing students demonstrated academic literacy 
in terms of linguistic, cognitive, and social-cultural dimensions in the written texts that they produced.

\section{Methods}

This study used a descriptive qualitative research design. The subjects were nursing students in a public university in Semarang, Indonesia. All of these students have started learning English since they were in elementary school. However, as English is considered a foreign language, a majority of them only study English in classrooms. The data in this study were collected from the students' written texts, which served as students' responses to an English quiz. Fifteen out of fifty-two students' texts were randomly selected for the analysis. The units of analysis included the texts, paragraphs, sentences, clauses, and words.

To analyze the data, a modified analytical score scale table by (Rajagukguk, T. E. B. et al., 2017) was used. The original version of this scale was developed by Tribble as cited in (Kern, 2000). This scale is a rubric which describes the assessment of texts based on the three dimensions of literacy: linguistic, cognitive, and socio-cultural. Each dimension has its own criteria and descriptors (excellent to very good, good, fair, and inadequate). In this study, the steps in analyzing the data included classifying the texts based on the text type, analyzing the texts based on the modified analytic score scales, and drawing inferences based on the results of the analysis. The findings and discussion were qualitatively presented.

\section{Results and Discussion}

This study evaluated the linguistic, cognitive, and socio-cultural dimensions of literacy in students' written texts. The majority of texts the students produced were the explanations of therapies or interventions in nursing. Some other students wrote procedural texts which describe how some interventions in nursing are carried out. The average word count of students' texts was 235 words, while the maximal and minimal word counts were 351 and 160 , respectively. The description of the data is presented in Table 1.

Table 1. The Description of Students' Written Texts $(n=15)$

\begin{tabular}{cllc}
\hline Texts & \multicolumn{1}{c}{ Title / Topic } & Text Type & $\begin{array}{c}\text { Word } \\
\text { count }\end{array}$ \\
\hline Text 1 & Deep breathing therapy & Procedure & 188 \\
Text 2 & Guided imagery therapy & Procedure & 213 \\
Text 3 & Warm compress intervention & Explanation & 160 \\
Text 4 & Breathing technique & Explanation & 221 \\
Text 5 & Deep breathing therapy & Procedure & 202 \\
Text 6 & Aromatherapy for decreasing stress & Explanation & 237 \\
Text 7 & Massage therapy to reduce pain & Procedure & 178 \\
Text 8 & Interventions for decreasing menstrual pain & Explanation & 264 \\
Text 9 & Interventions for decreasing menstrual pain & Procedure & 200 \\
Text 10 & Deep breathing technique & Explanation & 274 \\
Text 11 & Intra Muscular injection & Explanation & 351 \\
Text 12 & Assessment and intervention for patients with & Explanation & 259 \\
& menstrual pain & & \\
Text 13 & Nursing assessment & Procedure & 245 \\
Text 14 & Deep breathing therapy & Procedure & 285 \\
Text 15 & Intravenous injection & Explanation & 252 \\
\hline
\end{tabular}

In this study, two types of texts were analyzed: explanations and procedures. These texts are quite peculiar to students who learn a particular discipline of science, such as nursing. (Gerot \& Wignell, 1995) state that different areas employ a particular selection and pattern of genres or texts. In addition, (Curry, 2004) also argues that different disciplines have special rhetorical conventions, activities, communicative needs, and genres, such as reports, 
explanations, summaries, and argumentative essays (Kern, 2000). Students of nursing deal a lot with explanations and procedures in their study.

Three dimensions of literacy, i.e., linguistic, cognitive, and sociocultural, were observed. According to (Kern, 2000), the three dimensions of literacy are interweaved one to another so that it is difficult to separate each of them into clear-cut parts. However, to meet the purpose of the study, some descriptors were used to help observe each dimension.

\section{Linguistic Dimension of Literacy in Students' Texts}

The linguistic dimension of literacy in this study was assessed based on five aspects of writing forms and grammar: layout, spelling, verb conjugations and agreements, punctuation, and capitalization. Findings on each aspect are reported below.

In this study, it was expected that students wrote the essay using the appropriate layout of writing. However, the result of the analysis found evidence of inappropriate use of layouts. As essays normally consist of a number of paragraphs, which are indicated by an indentation of the first line of the paragraph or space between the first and following paragraphs, it is expected that students use either of these two. However, in this study, many students neither used indentation to start a paragraph nor space between the first and following paragraphs. Many wrote the essay in a single and lengthy paragraph, such as in Text 1 and Text 3 . In contrast, some other students wrote their texts either in two or three paragraphs, and clear indentation to start a new paragraph. Such inappropriate uses of layouts, as found in this study, were also reported in a study by (Rajagukguk, T. E. B. et al., 2017). In this study, it seemed that the students tried to use a space between the first and the following paragraph, but they missed to do so. A previous study argued that such a thing might occur due to students' carelessness (Rajagukguk, T. E. B. et al., 2017). How the students arranged their ideas in each paragraph might significantly influence readers' understanding. Thus, there should be a clear indication of one paragraph to the other one.

The way the students corrected their wrong sentences is also an interesting part that can be used to describe text layouts. In writing, crossing out the incorrect words, phrases, or sentences to indicate that they are incorrect and no longer used in the texts is normally used. Hence, the text will remain clean and neat. In this study, however, many students corrected their writing by over scratching the incorrect words that caused the texts to be less clean and neat. Such problems may cause difficulty in reading and may lead to issues when examiners are awarding marks, and thus may be hampering students' chances of exam success (Adams, 2016).

The next descriptor is related to spelling. Almost in all texts, problems of spelling were found. As emphasized by (Kern, 2000), familiarity with writing systems and graphics and organizational conventions is a part of the linguistic dimension. However, in this study, some students still used contractions, which should be avoided in their writing, such as "it's" instead of "it is," "don't" instead of "do not" and "can't" instead of "cannot." Many misspelled words were also present such as "incrase," "instruction," "patien," "relactation," "dictraction," and "potition." In this study, the use of misspelled words might be as a result of carelessness. However, there was evidence that some students used repeated misspelled words many times, indicating that it is not carelessness but the unfamiliarity of word spelling. This is an indication that the students are lack of linguistic knowledge (Kern, 2000; Rajagukguk, T. E. B. et al., 2017). As Odell, (1995) points out, incorrect uses of words in a text can cause the text to be less communicative.

Another issue in the students' texts is the use of verb conjugations and agreements. Since they are parts of linguistic knowledge, it is expected that the students are able to employ them in their written texts. In this study, it was evident that many students make repeated inappropriate uses of verb conjugations and agreements, such inappropriate use of finite and predictors, the missing finite, inappropriate use of prepositions, and inappropriate use of the subject-verb agreement. These repeated inappropriate practices could be an indicator of the lack of linguistic knowledge, for example, how to produce sentences using the simple present (Rajagukguk, T. E. B. et al., 2017; Watcharapunyawong \& Usaha, 2013). According to (GirónGarcía, 2015), when students practice literacy in a non-native language, they not only learn 
about vocabulary, grammar, and discourse; but they are also learning new ways to structure their thoughts. This can occur when students master the linguistic knowledge.

Furthermore, this study also revealed problems of English sentence structures, such as in Text 7. In this text, the student wrote, "Massage therapy with warm water is so easy to do." This clause may not sound English. It seems that there is an influence of the student's first language. Another example was found in Text 11, in which the student wrote: "Insulin is a substance that have a function of controlling the sugar blood of our body." In addition to the problem of finite, this clause also had a problem in the formation of a noun phrase. The phrase "sugar blood" was used by the student to replace the Indonesian phrase "gula darah." These findings are in line in line with a study by (Watcharapunyawong \& Usaha, 2013) which reported the first language interference errors of students in 16 categories: verb tense, word choice, sentence structure, article, preposition, modal/auxiliary, singular/plural form, fragment, verb form, pronoun, run-on sentence, infinitive/gerund, transition, subject-verb agreement, parallel structure, and comparison structure, respectively (Watcharapunyawong \& Usaha, 2013). Furthermore, Kern, (2000) also states that due to the differences in one language's writing system and conventions, learners who are able to write in a language is not necessarily able to write effectively in another language.

Punctuations and capitalization are important parts of the linguistic dimension. Punctuation marks as one of the typographical devices are used to convey certain functions, and capitalization functions to focus attention on particular elements within any group of people, places, or things (Gerot \& Wignell, 1995). Mastering the use of the punctuation mark and capitalization is important. Unfortunately, in this study, some inappropriate practices were indicated. Many students also inappropriately used full stops since they did not place the full stop exactly at the end of the sentence; instead, space seemed to exist between the last letter of the sentence and the full stop marker. This inappropriate practice can cause confusion for readers to understand the texts. In the case of capitalization, a few problems were indicated, such as inappropriate use of capitalization of the first letter at the beginning of a sentence, and in the middle of the sentence. The results in this study are congruent with a study by Darus and (Darus \& Ching, 2009), which reported problems of most common errors in mechanics, tenses, preposition, and subject-verb agreement in Chinese students who write essays written in English. Such problems indicated in this study urge a need for emphasizing the teaching of punctuation marks as well to make the learners get used to punctuation marks in written texts. Even though punctuation marks are considered as something trivial, it might cause confusion for readers if this is not noted (Rajagukguk, T. E. B. et al., 2017).

The results of the analysis indicated that the students in this study achieved a fair level of the linguistic dimension of literacy. They were partially able to use text layout, punctuations, capitalizations, and verb conjugations and agreement as well as the spelling in the texts they produced. However, there were some students who were indicated to have many problems with spelling and verb conjugations and agreement.

\section{Cognitive Dimension of Literacy in Students' Texts}

The second dimension of literacy in this study is the cognitive dimension. In this study, the cognitive dimension was assessed based on the students' responses to the task, treatment of the subject, information relevance, and interpretation that the students used in writing the texts. In this study, it was found that the majority of students could fully produce a text, either explanation, and procedures, to respond to the task. As confirmed by the subject instructor, the task required students to write essays about nursing for at least a half-page of folio paper, or at least 200 words. The majority of students wrote about deep breathing therapy to reduce pain while the other wrote essays about different interventions in decreasing pain and procedures of injection. Most of the texts are more than 200 words in length, and only two texts are less than 200 words.

Regarding the aspects of subject treatment, information relevance, and interpretation, it turned out that the majority of students had fairly sufficient information about the subject. They could provide an acceptable explanation about the subject even though some information in the text might be irrelevant, incomplete, or inaccurate. On the other hand, there were also 
students who performed fairly good in treating the subject and providing relevant information and interpretation. They could thoroughly describe the subject and provide relevant and accurate information and interpretation. Such an example is found in Text 10 about deep breathing to decrease anxiety. In text 10, it was found that the student explained the importance of deep breathing, the primary steps to do, and certain conditions required so that deep breathing can bring optimum effects. In his text, the student could provide a thorough treatment of the subject and relevant information and accurate interpretation. Similar issues were also identified in Student11 and Student14. On the other hand, there also students who did not provide a thorough treatment of the subject. Irrelevant information and inaccurate interpretation were also indicated. It seemed that the students had very little information about the subject that they wanted to write. As a result, the texts produced were very short and missed important information that readers need to know. In practicing literacy in a non-native language, students need to learn not only about vocabulary, grammar, and discourse; but they are also learning new ways to structure their thoughts (Girón-García, 2015).

In this study, there was evidence that the ability of students to produce texts is greatly influenced by the cognitive dimension. Some students may write fairly well since they have already had information on a particular subject that they intend to write and how to transform that into text. However, some other students may seem to find it hard to write, which probably due to the lack of information about the subject and the procedure of how to write. As pointed out by (Kern, 2000), existing knowledge becomes the central importance in the cognitive dimension, which consists of declarative (knowing what) and procedural (knowing how) knowledge. Declarative knowledge consists of ideas, concepts, facts, and definitions one can draw to make sense of a text or to write about a particular topic, while procedural knowledge has to do with one's ability to do things he wants to do. Both types of knowledge play an important role in one's academic written texts and are organized systematically in mind. Someone employs this knowledge based on the purposes and goals, which are associated with the metacognitive components of cognitive processing such as planning, monitoring and revising in both reading and writing (Kern, 2000). Moreover, (Henderson \& Hirst, 2007) also reported that writing is a skill that is grounded in the cognitive domain as it involves learning, comprehension, application, and synthesis of new knowledge. The cognitive activity is associated with mental processes and strategies activated during the reading and writing activity, i.e., discovering and creating the meaning. Reading activities stimulate thinking and expand knowledge connecting the old with the new information. To read means to process new contents, understand concepts and relations, follow a different way of thinking, memorize, and use new knowledge (Knaflič, 2014). Reading helps students get information and has many advantages, such as broadening knowledge and finding solutions to a problem (Hastuti \& Yuliasri, 2015). Therefore, someone who fails in reading might mean that he/she fails in receiving relevant information about a particular subject, and would probably find difficulties in writing due to the lack of information about the subject.

Regarding the cognitive dimension, results indicated that the students showed a fair level of cognitive dimension. Students in this study provided a less complete response to the task and sometimes irrelevant information and inconsistent interpretation about the subject of the text. They should be given more exposure on how to comprehend a subject by reading and communicate the knowledge they get through the text.

\section{Socio-cultural Dimension of Literacy in Students' Texts}

The third dimension of literacy in this study is the social-cultural dimension. This dimension was assessed based on the students' knowledge or familiarity with the genre that they produce and language appropriateness. Generic structures and lexico-grammatical features are two main aspects that become the center of attention in this part. In this study, the types of students' texts were explanation and procedure. The generic structure of the former text consists of two main parts: general statement and sequenced explanation, while the latter consists of goals and steps. Regarding the lexico-grammatical features, the explanation text includes the focus on generic and non-human participants, use of mainly material and relational processes, use of temporal and causal circumstances and conjunctions, use of 
simple present tense, and some use of passive voice. Meanwhile, the procedure consists of goals and steps (Gerot \& Wignell, 1995).

In this study, most students producing explanations followed the generic structures of the text. Similarly, the majority of students with procedural texts also followed the generic structure of the text. Some students wrote the title of the text to indicate the goal or the purpose of the procedure and then followed by a sequenced explanation of the procedure steps. Though some other students did not mention the title, the goal of the text can still be identified in the explanation written in the text. It seems that familiarity with genre gives important value for the students to write on the right track. By learning the schematic structure of a text, students can become a good controller over different text types (Manikowati \& Bharati, 2017; Wu \& Dong, 2009). The students seemed to have a good comprehension of a procedural text. This might be due to the reason that these students were sufficiently exposed to a task that requires them to demonstrate nursing skills or nursing interventions in the laboratory. Before doing so, usually, they write a scenario, and the scenario is mostly procedural. This influences students' understanding of how to produce such texts.

Most students in this study were doing good in generic structure. However, in relation to explanation texts, some inappropriate practices of the generic structure were indicated. It is apparent that in some texts, what readers expect to happen next in the text does not finally occur. According to (Kern, 2000), when a text is produced out of what is assumed or expected, it can cause broken comprehension for the readers.

Another important issue to discuss is dealing with the lexico-grammatical features of the text. In this study, regarding the explanation text, all texts are focused on non-human participants, particularly on interventions or therapies in nursing of various kinds. All students in this study wrote texts about nursing as required by the task. That means the students did not write about a person in particular, but they wrote about therapy/intervention, which does not represent humans. They also used material and relational processes. Material processes express the notion that some entity physically does something, while relational processes express the notion of being or having (Gerot \& Wignell, 1995). In the explanation text, the use of the material and relational processes is required. However, on some occasions, there was evidence that the students used verbal and mental processes in their texts, which might be due to incomplete familiarity with the genre.

Another lexicogrammatical feature of explanation is the use of temporal and causal circumstances and conjunctions. Temporal conjunctions include words or phrases which are used to tell readers when something is happening, while causal circumstances and conjunctions are used to introduce a cause for a given action or result in a sentence (Gerot \& Wignell, 1995). In this study, there was evidence that the students used temporal and causal conjunctions in the texts. Many students used such temporal conjunctions as "when," "before," and "after" or causal conjunctions as "because," "so," "but," "otherwise" and "if." Though there was evidence that the students used causal circumstances and conjunctions in writing the texts, evidence of inappropriate uses was also indicated. Some students inappropriately used causal conjunctions, such as putting "because," "so" and "but" at the beginning of the sentence. These inappropriate practices might happen because the students did not accustom to the written mode of communication. Another factor might be because the students focus too much on how to fulfill the task, and thus they pay less attention to the way the texts are arranged (Rajagukguk, T. E. B. et al., 2017).

The use of simple present tenses and passive voice are other lexico-grammatical features of explanation text. In this study, there is evidence that the students use simple present in writing the explanation. Not all sentences written in present tenses are grammatically correct, but there is a tendency that most students use present tenses throughout the text. It seems that students have received fairly good exposure on the use of the simple present to describe general phenomena or truth. However, on very few occasions, the use of past tenses is also indicated.

Regarding the use of passive voice, there was evidence that the majority of students used passive voice in their texts. However, the grammatical structure of the passive voice is not perfectly used. Some students missed or misused "to be" or past participle in their 
sentences. The limited use of passive voice, perhaps, happens because the idea of using passive voice did not come across in students' minds (Rajagukguk, T. E. B. et al., 2017). In fact, as the texts should provide an explanation about non-human participants, passive voice is needed (Gerot \& Wignell, 1995). The students need to be exposed more to the use of passive voice in describing non-human participants.

Regarding the procedural texts, the lexico-grammatical features which are important to discuss are the use of temporal conjunctions and mainly material processes. In this study, it was evident that all students used temporal conjunctions in their texts. The most common types of temporal conjunctions found in the texts in this study are "then," "first...", "and then" "after that", "next" and "before doing that." Some students used repeated conjunctions in their text for many times. It seemed that the students could appropriately use the conjunctions. However, the variety of use of these conjunctions is very minimal.

The last feature of the procedural text is the use of material processes. Material processes express the notion that some entity physically does something (Gerot \& Wignell, 1995). In this study, all procedural texts were evident to use material processes. It seemed that the students could use the material processes fairly well to indicate that certain actions should be carried out. However, on some occasions, the students did not properly use the materials processes. Instead of using the verb "instruct," for example, a student used "instruction" to start the step of the procedure. Therefore, she wrote, for example, "Instruction the patients to close their eyes" and "Instruction the patient to take breath by nose." By observing the text, it seems that there is confusion in the student' mind of using verb or noun as to differentiate between "instruct" and "instruction." This is most possible because of the limited ability of the student's linguistic competence.

The language appropriateness of the text describes the suitability of the language of the genre with the context of communication. In this study, there was evidence that a majority of the texts had some problems with language appropriateness. In nursing, for example, an alternative intervention for decreasing pain or body temperature is compress, either warm compress or cold compress. However, some students use the term "hot compress" instead of "warm compress" to name the intervention. Another example is the use of "TTV" that actually means "Tanda-tanda vital" and "vasokontriksi". It seemed that the student mixed the use of Indonesian language in the text. The findings in this study is in line with a study by (Chimbganda, 2011) which reported that the use of vocabulary has been a common problem in ESL students' writing.

In this study, it was evident that some students inappropriately used the language of the genres. Such problems occured possibly due to the lack of linguistic competence or familiarity with the given genres (Rajagukguk, T. E. B. et al., 2017). According to (Kern, 2000), genres are important to be mastered by the students as they set the parameters of "appropriateness of language use". Furthermore, Marinkovich et al., (2016) stated that familiarity with genres helps students perform more optimal in their academic as they are mostly required to interact with different categories of texts of different genres and modes. Another possible reason is the first language interference as pointed out by Kern, (2000), that due to the differences in one language's writing system and conventions, learners who are able to write in a language is not necessarily able to write effectively in another language or the target language. Moreover, as Odell, (1995) points out, incorrect uses of words in a text can cause the text to be less communicative.

The sociocultural dimension of literacy demonstrated in the students' texts was generally at a fair level. Most of them seemed to be familiar with the types of texts and their generic structures as well as linguistic features. However, students need to learn more about how to use various causal circumstances and conjunctions in writing explanation texts.

The results of this study encourage the need to develop the literacy of the nursing students in English language. As English was perceived very important for students both in their academic studies and future careers Nurakhir \& Palupi, (2018), it is then important for both students and teachers to work cooperatively to deal with this issue. The way the students learn and increase their literacy will be very much influenced by the teaching and learning process in which the students are involved; therefore, as educators, teachers play an important 
role to make the learning meaningful, interesting, creative, dynamic, and interactive (Faridi et al., 2016).

\section{Conclusion}

After analyzing the students' texts, it could be concluded that in general, the texts that students produced showed a fair level of linguistic, cognitive and socio-cultural dimensions of literacy. In this study, students were found to be partially able to use layouts, punctuations, capitalizations, and verb conjugations and agreement as well as spelling. A majority of them seemed to be familiar with the types of texts and their generic structures as well as linguistic features. However, it was found that students provided a less complete response to the task and sometimes irrelevant information and inconsistent interpretation about the subject of the text.

Based on the results of the study, it is recommended that the students be given more exposure on how to comprehend a subject by reading and communicate the knowledge they get through the text. They also need to learn about how to use various causal circumstances and conjunctions in writing explanation texts. The results of this study also indicate that there is a high need for nursing students to improve their ability in academic literacy in English. Academic literacy is not a natural phenomenon but a learned ability, and thus it should be fostered in the educational institutions.

\section{References}

Adams, R. (2016). Poor handwriting 'may hinder students' chances of exam success. Https://Www. Theguardian.Com/Education/2016/Aug/22.

Barton, D. (2007). Literacy: An introduction to ecology of written language. Oxford: Blackwell Publishing.

Chimbganda, A. B. (2011). Discovering academic literacy skills in English of first year ESL students in humanities at the University of Botswana. International Journal of Linguistics, 3(1), 1-21.

Curry, M. J. (2004). UCLA community college review: academic literacy for english language learners. Community College Review, 32(2), 51-68. https://doi.org/10.1177/009155210403200204

Darus, S., \& Ching, K. H. (2009). Common errors in written english essays of form one Chinese students: A case study. European Journal of Social Sciences, 10(2), 242-253.

Defazio, J., Jones, J., Tennant, F., \& Hook, S. A. (2010). Academic literacy: The importance and impact of writing across the curriculum - A case study. Journal of the Scholarship of Teaching and Learning, 10(2), 34-47. https://doi.org/https://eric.ed.gov/?id=EJ890711

Faridi, A., Bahri, S., \& Nurmasitah, S. (2016). The problems of applying student centered syllabus of English in vocational high schools in Kendal Regency. English Language Teaching, 9(8), 231-240. https://papers.ssrn.com/sol3/papers.cfm?abstract_id=2822214

Gao, L. H. (2017). Academic literacy acquisition beyond cultural boundaries: Taking academic English writing as a case. Proceeding of 3rd International Conference on Education and Social Development (ICESD 2017). http://dpiproceedings.com/index.php/dtssehs/article/download/11583/11125.

Gerot, L., \& Wignell, P. (1995). Gerot, L. \& Wignell, P. Stabler.

Girón-García, C. (2015). Literacy and technologies in EFL settings: Fostering reading comprehension on the Internet. Bellaterral Journal of Teaching \& Learning Language \& Literature, 8(2), 69-100. https://doi.org/10.5565/rev/jtl3.616

Hastuti, D., \& Yuliasri, I. (2015). The effectiveness of STAD and TGT to enhance narrative text reading comprehension of the students with high and low achievement. English Education Journal, 5(2), 46-52. https://lib.unnes.ac.id/32995/ 
Henderson, R., \& Hirst, E. (2007). Reframing academic literacy: Re-examining a short-course for "disadvantaged" tertiary students. English Teaching: Practice and Critique, 6(2), 2538. https://eprints.usq.edu.au/2869/

Hyland, K. (2007). Genre pedagogy: Language, literacy and L2 writing instruction. Journal of Second Language Writing, 16, 148-164. https://doi.org/10.1016/j.jslw.2007.07.005

Kern, R. (2000). Literacy and language teaching. Oxford University Press.

Knaflič, L. (2014). Psychological Aspects of Literacy. Libellarium, 7(1), 41-53. https://doi.org/10.15291/libellarium.v7i1.195

Kress, G. (2003). Literacy in the new media age. Routledge.

Lea, M. R., \& Street, B. V. (1998). Student writing in higher education: An academic literacies approach. Studies in Higher Education, 23(2), 157-172. https://doi.org/10.1080/03075079812331380364

Lea, M. R., \& Street, B. V. (2006). he "academic literacies" model: Theory and applications. Theory into Practice, 23(2), 368-377. https://doi.org/10.1207/s15430421tip4504_11

Lillis, T., \& Scott, M. (2007). Defining academic literacies research: issues of epistemology, ideology and strategy. Journal of Applied Linguistics, 4(1), 5-32. https://doi.org/10.1558/japl.v4i1.5

Manikowati, \& Bharati, D. A. L. (2017). The effectiveness of multimedia in teaching writing to students with different learning styles. English Education Journal, 7(2), 85-91. https://doi.org/10.23887/jpi-undiksha.v9i3.17736

Marinkovich, J., Velásquez, M., Córdova, A., \& Cid, C. (2016). Academic literacy and genres in university learning communities. Ilha Do Desterro, 69(3), 95-113.

Mujiyanto, Y. (2013). The significance of academic literacy in analysing texts for translation. Language Circle Journal of Language and Literature, 7(2), 65-73.

Nurakhir, A., \& Palupi, F. N. (2018). Exploring ESP needs of undergraduate nursing students in a university in Indonesia. Advances in Social Sciences Research Journal, 5(7), 7785. https://doi.org/10.14738/assij.57.4276

Odell, L. (1995). Basic writing in context: Rethinking academic literacy. Journal of Basic Writing, 14(1), 43-56. https://www.jstor.org/stable/43443648

Palmer, L., Levett-Jones, T., Smith, R., \& McMillan, M. (2014). Academic literacy diagnostic assessment in the first semester of first year at university. The International Journal of the First Year in Higher Education, 5(1), 67-78. http://hdl. handle.net/10453/116495

Papashane, M., \& Hlalele, D. (2014). Academic literacy: A critical cognitive catalyst towards the creation of sustainable learning ecologies in higher education. Mediterranean Journal of Social Sciences. https://doi.org/10.5901/mjss.2014.v5n10p661

Piršl, D., Piršl, T., \& Kesić, D. (2011). Writing skills at university level. Sportlogia. Sportlogia, $7(1), 69-72$.

Rahayu, A., \& Arrasyid, I. (2016). Exploring writing practices in EFL classroom: A case study at English Department IAIN Syekh Nurjati Cirebon. ELT-Echo, 1(1), 53-64. https://doi.org/10.24235/eltecho.v1i1.968

Rajagukguk, T. E. B., Agustien, H. I. R., \& Mujiyanto, Y. (2017). The academic literacy of sixteen-seventh graders of an English immersion junior high school in Semarang. Language Circle: Journal of Language and Literature, 11(2), 198-214. https://doi.org/10.15294/lc.v11i2.9592

Watcharapunyawong, S., \& Usaha, S. (2013). Thai EFL students' writing errors in different text types: The interference of the first language. English Language Teaching, 6(1), 67-78. https://doi.org/10.5539/elt.v6n1p67

Wells, G. (1987). Apprenticeship in Literacy. Interchange, 18, 109-123.

$\mathrm{Wu}, \mathrm{Y}$., \& Dong, H. (2009). Applying SF-based genre approaches to English writing class. International Education Studies, 2(3), 77-81. https://eric.ed.gov/?id=EJ1065736 